\title{
STUDI KUALITATIF : IDENTIFIKASI KEBUTUHAN PERAWATAN BAYI BBLR DI RUMAH DENGAN PENDEKATAN FAMILY CENTERED MATERNITY CARE
}

\section{QUALITATIVE STUDY: IDENTIFICATION OF LOW BIRTH WEIGHT BABY CARE NEEDS AT HOME WITH FAMILY CENTERED MATERNITY CARE APPROACH}

\author{
Ratna Widhiastuti ${ }^{\circledR}$, Susi Muryani \\ Nursing and Nurses Undergraduate Study Program Bhamada Slawi University. Indonesia \\ Correspondence Email : ratnawidhiastuti@gmail.com
}

\begin{abstract}
ABSTRAK
Bayi Berat Badan Lahir Rendah (BBLR) memerlukan perawatan lebih khusus dibandingkan dengan bayi lahir dengan berat badan normal, hal ini terlihat dari beberapa ibu yang kembali ke RSI Muhammadiyah Tegal karena ibu kurang memahami tentang perawatan bayi BBLR di Rumah. Family Centered Maternity Care (FCMC) adalah perawatan yang berpusat pada keluarga dengan memberikan perawatan bagi wanita dan keluarga mereka yang mengintegrasikan kehamilan, persalinan, persalinan, dan perawatan bayi ke dalam kontinum kehidupan keluarga.Tujuan penelitian ini untuk mengidentifikasi kebutuhan perawatan bayi BBLR di rumah dengan pendekatan family centered maternity care secara studi kualitatif. Penelitian dilakukan di RSI PKU Muhammadiyah Tegal. Metode dengan kualitatif dengan design studi kasus menggunakan ibu dan keluarga yang bayi BBLR sebanyak 9 orang dan focus group discussion (FGD) pada 7 perawat perinatologi. Berdasarkan hasil analisa Colaizzi didapatkan beberapa tema yaitu dukungan keluarga untuk meningkatkan kepercayaan diri ibu merawat bayi BBLR, strategi pemenuhan kebutuhan nutrisi, strategi mencegah terjadinya hipotermia, upaya mencegah terjadinya infeksi, home visit perawat. Peningkatan perhatian untuk menjaga bayi BBLR tetap hangat dalam bentuk FCMC berintergrasi pada ibu, keluarga serta perawat dapat mengoptimalkan perawatan Bayi BBLR di rumah.
\end{abstract}

Kata Kunci : Bayi BBLR; family centered; maternity care, mother

\section{ABSTRACT}

Babies with low birth weight require more special care than babies born with normal weight; this can be seen from some mothers who return to RSI Muhammadiyah Tegal because mothers do not understand how to care for low birth weight babies at home. Family Centered Maternity Care (FCMC) is family-centered care providing care for women and their families that integrates pregnancy, childbirth, childbirth, and infant care into the continuum of family life. The purpose of this study was to identify the care needs of low birth weight baby at home with a family centered maternity care approach in a qualitative study. The research was conducted at Muhammadiyah Hospital Tegal. Qualitative method with case study design was used in 9 mothers and families of low birth weight babies and focus group discussion on 7 perinatology nurses. Based on the results of Colaizzi's analysis, several themes were found, namely family support to increase mother's confidence in caring for low birth weight babies, strategies to fulfill nutritional needs, strategies to prevent hypothermia, efforts to prevent infection, nurse home visits. Increased attention to keeping low birth weight babies warm in the form of Family Centered Maternity Care with interaction with mothers, families and nurses can optimize the care of low birth weight babies at home.

Keywords: low birth weight babies; family center; maternity care; mother 


\section{PENDAHULUAN}

Angka Kematian Bayi (AKB) merupakan indikator yang digunakan untuk menunjukkan keadaan dari derajat kesehatan di suatu masyarakat, di antaranya pelayanan ibu dan bayi (Badan Pusat Statistik Jawa Tengah, 2019). 7000 bayi lahir di dunia meninggal setiap harinya, sedangkan di Indonesia angka kematian neonatal 15 per 1000 kelahiran hidup (WHO, 2018) indikator yang dapat digunakan sebagai tolak ukur kesehatan bayi seperti memprediksi risiko penyakit anak kesehatan, pertumbuhan, dan perkembangan masa depan anak, dan kemungkinan bertahan hidup adalah dengan mengetahui berat bayi yang baru lahir (Deshpande, J, 2011).

Bayi Berat Badan Lahir Rendah (BBLR) 20 kali lebih mungkin mengalami komplikasi dan meninggal dibandingkan dengan bayi lahir dengan berat normal. BBLR memilki resiko terjadi defisit kognitif, keterlambatan motorik, cerebral palsy, gangguan pada sistem pernafasan, susunan saraf pusat, kardiovaskular, hematologi, gastrointestinal, ginjal, termoregulasi dan masalah perilaku ( Mathewshon, KJ 2017: Chang H Y et al 2015). Bayi yang terlahir kecil memerlukan penanganan khsusus agar agar tidak terhambat pertumbuhannya atau yang dikenal dengan istilah stunting (Benson Atitwa, 2015). Bayi BBLR merupakan salah satu faktor resiko utama terjadinyastunting pada balita. 1000 hari pertama kehidupan merupakan periode kritis perkembangan anak, dimulai dari saat konsepsi hingga pasca persalinan, ini ditentukan oleh pematangan dari metabolik yang berpengaruh terhadap pertumbuhan dan perkembangan anak. Jika terjadi masalah infeksi atau kurang optimal, pertumbuhan anak dapat terganggu, menyebabkan gizi buruk, yang dapat bermanifestasi sebagai atau sebagai kekurangan gizi (Ruairi, C Robertson, 2019)

WHO menyatakan 15\% hingga 20\% Bayi terlahir BBLR.Prevalensi BBLR bervariasi antar wilayah dengan 28\% tertinggi di Asia Selatan dan terendah 6\% di Asia Timur dan wilayah Pasifik. Indonesia BBLR merupakan penyebab utama angka kematian nenoatal yaitu sebanyak 7150 kelahiran atau 35\%. Di Jawa Tengah kasus BBLR sebanyak 24\% ( Kementerian Kesehatan, 2019) Persentase BBLR di Kabupaten Tegal sebesar 7,36\% (Dinas Kesehatan Kabupaten Tegal, 2018). Intervensi untuk mengurangi kekurangan gizi dan mencegah prematuritas dan BBLR adalah mendorong stimulasi dini untuk perkembangan optimal (Ahishakiye et al., 2019). Pengetahuan lbu terkait perawatan optimal pada BBLR dapat ditingkatkan melalui praktek edukasi, diskusi, dan penggunaan teknologi sebagai media pembelajaran merupakan cara untuk mencegah dampak stunting sebagai upaya peningkatan pengetahuan dan kepercayaan diri ibu dalam merawat BBLR (Sugiarti, 2020). Family Centered Maternity Care (FCMC) adalah perawatan yang berpusat pada keluarga dengan memberikan perawatan bagi wanita dan keluarga mereka yang mengintegrasikan kehamilan, persalinan, dan perawatan bayi ke dalam kontinum kehidupan keluarga. FCMC dilakukan untuk mengoptimalkan kemampuan ibu dalam perawatan diri dan perawatan bayi baru lahir [International Childbirt Education Association, 2018)

Sistem pendukung keluarga dapat menjadi alat yang potensial untuk sistem informasi manajemen kesehatan (Jamejaya, S, 2016). Sejauh ini belum ada penelitian yang berfokus pada identifikasi perawatan bayi BBLR di Rumah. Riset ini penting dilakukan karena identifikasi kebutuhan perawatan bayi BBLR, akan menghasilkan informasi perawatan BBLR yang komperhensif. Perawatan Bayi BBLR yang dilakukan ibu maupun keluarganya sehingga dapat mengurangi bayi BBLR beresiko mengalami stunting dan komplikasi lainnya. Berdasarkan permasalahan diatas, penelitian ini dilakukan untuk mengidentifikasi kebutuhan perawatan bayi BBLR di rumah dengan pendekatan family centered maternity care secara studi kualitatif.

\section{METODE}

Penelitian ini dilakukan secara kualitiatf dengan design studi kasus. Penelitian ini dilakukan di RSI PKU Muhammadiyah Tegal. Pertimbangan peneliti memilih lokasi penelitian adalah karena merupakan Rumah Sakit yang memiliki angka Bayi BBLR cukup besar yaitu 30 pasien setiap bulan, dan mendukung FCMC ditandai bayi dapat dilakukan perawatan rawat gabung dengan ibu.

Penelitan ini menggunakan informan Ibu dan keluarga yg memiliki bayi BBLR sebanyak 6 - 10 rang dan FGD pada perawat yang bertugas di ruang perawatan bayi baru lahir. Teknik pengambilan data secara wawancara mendalam pada lbu postpartum (informan utama) beserta keluarga (informan pendukung) yang memiliki bayi BBLR yang dirawat di RSI PKU Muhammadiyah Tegal dan focus group discussion pada perawat (informan pendukung) yang bertugas di ruang bayi BBLR. Penentuan informan dalam penelitian ini dilakukan melalui tenik purposive sampling. Wawancara mendalam dilakukan dengan menggunakan instrumen pedoman wawancara dan alat perekam suara. Selain itu, peneliti juga mempersiapkan kamera maupun alat tulis untuk mendokumentasikan kegiatan selama pengambilan data berlangsung.

Analisa data dilakukan menggunakan metode ini menggunakan Colaizzi.Keabsahan data dalam penelitian ini dilakukan melalui 
metode triangulasi sumber dan member checking. Triangulasi sumber dilakukan dengan melakukan wawancara dari sumber data informan utama maupun informan pendukung, sedangkan member checking dilakukan dengan pengambilan data lebih dari sekali pada setiap informan agar informan mampu memberikan feedback dan tidak adanya bias pemahaman dari peneliti terhadap apa yang sudah disampaikan oleh informan.

Penelitian ini mengkaji kebutuhan perawatan bayi BBLR di rumah dilihat dari sisi ibu, keluarga dan perawat. Bentuk pertanyaan wawancara mendalam diantaranya yaitu bagaimana presepsi ibu dan keluarga, bagaimana dukungan fisik dan psikologi, bagaimana cara mempertahankan lingkungan yang mendukung perkembangan bayi dan identifikasi pendidikan kesehatan apa saja yg diberlukan berkaitan tentang perawatan BBLR. Nomer etik penelitian 0431/II.6.AU/F/2020.

\section{HASIL}

Berdasarkan hasil penelitian didapatkan berbagai tema yaitu dukungan keluarga untuk meningkatkan kepercayaan diri ibu merawat bayi BBLR, strategi pemenuhan kebutuhan nutrisi, strategi mencegah hipotermi, upaya meminimalisir terjadinya infeksi, home visit perawat

\section{Dukungan keluarga untuk meningkatkan kepercayaan diri ibu merawat bayi BBLR}

Support dan dukungan keluarga seperti
memberikan semangat, perhatian,
dibutuhkan ibu dalam merawat bayi BBLR seperti
yang disampaikan oleh beberapa partisipan
dibawah ini
"Dari keluarga memberikan dukungan dengan
cara suruh sabar yang penting sehat seperti
anak yang lain", P6
"Harus sabar, jangan pesimis iri atau
bagaimana, banyak banyak doa, rawatlah cepet
gede" P7
"Supportnya dikasi tahu harus sabar, harus kuat nanti juga besar, kalau sudah menyusui nanti kan bertambah beratnya" $P 5$

"Mulai sekarang gak boleh capek, harus semangat, agar menambah bobotnya"P3

"Suport dari keluarga adalah paling ya sama sama berdoa agar bayi sehat agar sama seperti bayi bayi yang lain" P2

"Ibu perlu support mental kalau ibu bisa merawat bayi BBLR, dari keluarga dan ibunya"P4

"Paling itu support keluarga suami ibunya ngasi semangat ke ibunya ya kalau makan atau apa biar ibunya $g$ steess jadi merawat bayinya seneng, jadi edukasi ke keluarga agar tidak membebani pikiran ibunya.. ( biasanya disuruh ini, disuruh itu).."P1
Keluarga yang berpengalaman dalam merawat bayi BBLR, memiliki kesiapan dalam merawat bayi BBLR seperti pernyataan partisipan berikut ini

"Saya selalu ngasi semangat ya keadaan anak kayak gini kan masukan sedikit karena terutama jaga kesehatan, biasanya kalau timbangan kurang 2,5 dikasih asi tiap 1 jam, diberi penghangat, kalau dulu saya pakai philips, agar anak dekat dengan ibu biar nempel ke ibunya, 1jam ditempelkan ke dada bayi ibu, dan tidak pernah saya mandikan ,.kalau adiknya nangis , saya lapin pakai minyak telon, kalau eek baru pakai air anget, Anak saya berikan makanan bergizi, mau jalan bulan 7 yang penting sayur ikan susu, saya mandikan baru berat $3,5 \mathrm{~kg}$ kalau berat badan nya terkaku kecil tidak tahan angin" $\mathrm{K} 8$

\section{Strategi Pemenuhan kebutuhan Nutrisi}

Beberapa partisipan menyampaikan kebutuhan pemenuhan nutrisi sangat penting untuk meningkatkan berat badan bayi seperti bagaimana cara pemberian asi, cara pemberian nutrisi dengan menggunakan OGT, cara melakukan pijat reflek hisap sehingga bayi mudah meminum asi seperti pernyataan partisipan berikut ini

"Cara netek kan belum kenceng, baru diujungnya bagaimana caranya agar neteknya kenceng, bagaiman caranya agar asinya keluar banyak agar dedeknya sehat"P8

"Bagaimana cara menaikan berat badan bayi, karena asinya belum keluar" P6

Berdasarkan hasil FGD beberapa perawat menyampaikan pemberian nutrisi merupkaan indikator yang penting untuk meningkatkan berat badan bayi BBLR seperti pernyatan partisipan dibawah ini

"Permasalahannya di nutrisi dan hipertemi, bahkan sampai ada di rumah perawatan ibu kurang ke bayinya sampai masuk ke rumah sakit lagi yang hipotermi bayi, gulanya rendah mungkin karena reflek hisapnya bayi hilang timbul, sedangkan di rumah si bayi lupa cara mengenyot ke ibu, kalau di rumah sakit ada tambahan NGT atau yang lain jadi kalau di rumah sakit edukasinya ditambahkan lagi" Perawat 7

"Bayi BBLR dengan NGT kalau bisa menyengot 2 jam sekali di susui sesering mungkin meski bayi tidur Agar asi berkualitas ibu mengkonsumsi asi, sama suami menambah per, banyak makan sayuran suami membelikan atau mencarikan sayuran Bayi pulang dengan NGT ditarget beberapa jam mengharuskan Mungkin untuk asi, cara penyajian asi bagaimana, cara menghangatkan asinya bagaimana" Perawat 3 
"Asi agar lancar buat ibu senang, dukungan dari keluarga ibu senang bayi senang asinya lancar Cuman ditekankan sama suaminya, membantu mensuport selain dengan NGT dan sufor lagi untuk meningatkan susu infatri berat badan Kalau asi ga keluar, bisanya dilakukan pijat oksitosin, dipijet berarti kalau ada masalah asi tidak lancar penanganan di ruangan biasanya kita motivasi ibu untuk jangan stress, lakukan pijat oksitosin kalau dirumah harus sesering mungkin diberi asi" Perawat 1

"Kalau belum ada reflek hisap kalau pulang bawa ngt cara memberian asinya kita beri edukasi cara agar cepat besar bagaimana, gendong bagaimana cara menyusui bagaimana" Perawat 4

"Pemberian asi Dari dokter seperti bayi baru lahir bb kurang dari $1 \mathrm{~kg}$, target dilatih ibunya berapa cc coba dilatih botol coba dilebih ngenyot ke ibunya langsung sisanya itu ke ibu, target tersendiri, kalau mencukupi biasanya naik Target asi yang harus terpenuhi "Perawat 5

\section{Strategi mencegah terjadi hipotermi}

Memberikan kehangatan bayi seperti melakukan KMC, menjemur bayi merupakan upaya yang dapat dilakukan agar tubuh bayi BBLR tetap hangat dan seperti pernyataan partisipan berikut ini

"Cara berpakaiannya, kita tidak tahu bayi prematur yang harus dilakukan bagaimana, apa saja yang harus dikonsumsi agar berat badan naik"P9

"Yang berkaitan tentang ibu dan anak,tantangan makanan untuk ibu, cara merawat agar bayinya lebih sehat, kalau dirumah paling itu harus dijemur atau diberi penghangat" P8

Berdasarkan hasil FGD ada sebagian perawat yang menyampaikan melakukan KMC merupakan edukasi yang dapat diberikan kepada ibu dan keluarga sebelum pulang ke rumah agar KMC dapat dilakukan tidak hanya di rumah sakit tetapi di rumah, KMC sendiri dapat dilakukan tidak hanya ibu, tetapi keluarga bayi BBLR dengan syarat keluarga sehat, dan tidak merokok.

"Untuk bayi BBLR seperti yang disampaikan nutrisi, perubahan suhu tubuh karena bayi dipisah lama reflek hisap kurang dan banyak keluarga dari ibu bayi kurang pengetahuan keluarga dengan merawat bayi kecil jadi mereka masih kebingungan dalam merawat bayi BBLR"Perawat 6

"menghangatkan bayinya, kalaupun ada inkubator tetap dihangatkan, untuk ibuya itu tetap melakukan Kangguru kalau ibunya capai bisa digantkan dengan keluarga inti yang lain yang tidak mempunya masalah ke kesehatannya., kalau asi satu sudah memenuhi banyak asinya di pompa, sisanya dimasukan dikulkas, reflek hisapnya tetap bayinya dipijat area pipi dagu tetap ada reflek hisapnya , agar reflek hisapnya bagus juga" Perawat 4

"Bagaimana agar memandikan diusahakan disesuaikan kalau dingin yan cukup dilap, edukasi PMK kalau pulang PMK gak cuma sama ibu bayinya tetapi juga sama keluarga kalau ada masalah perbedaan persepsi PMK selama ini kita kira memberikan edukasi ke pasien, apa lagi yang kira kira salah persamaan persepsi" Perawat 7

"Kayak edukasi kalau chek gula normal, nanti PMK gak harus sama ibunya, ayahnya jangan merokok,, kalau keluarga tidak ada lagi, suaminya terakhir tetapi tidak merokok," Perawat 2

\section{Upaya pencegahan terjadinya infeksi}

Bayi BBLR membutuhkan perlindungan untuk mengurangi resiko terjadiya infeksi pada bayi, upaya yang dilakukan dengan cara mencuci tangan, membatasi jumlah kunjungan orang lain ke rumah, seperti pernyataan partisipan berikut ini

"Yang ingin diketahui ya namanya saya orang awam kurang banyak tahu, setelah dedeknya pulang bagaimana caranya perawatan yang belum tahu, jaga kebesihan semaksimal mungkin" P2

Beberapa perawat menyampaikan pencegahan infeksi dengan membatasi jumlah pengunjung dirumah, mencuci tengan sebelum memang bayi merupakan upaya yang dapat dilakukan agar kondisi bayi selalu sehat saat dirawat di rumah berikut pernyataannya

"Pertama setiap mau memegang bayi mewajibkan cuci tangan setiap memegang bayi, karena bb bayi riskan resiko infeksi"Perawat 3

"Kalau anggota keluarga lain yang tidak enak badan sakit, kalau ada anak kecil yg lain ada adeknya dikurangi dulu"Perawat 4

"Kalau bayi baru lahir biasanya kita edukasi jangan dijengkuk dulu sampai bb normal" Perawat 1

\section{Home Visit Perawat}

Pasien sudah pulang ke rumah, pemberian perawatan pada ibu dan bayi dapat dilakukan perawat dengan melakukan kunjungan ke rumah atau home visit untuk mengetahui perkembangan kondisi bayi dan ibu, adanya support dari perawat dapat 
mengoptimalkan peningkatan berat badan bayi berikut pernyataan partisipan

"Kunjungan / home visit dalam merawat bayi kalau kunjungan kita evaluasi berat badan ada naik, PMK dijalankan atau tidak kita evaluasi karena sekarang masih pandemi, terutama bayi kurang dari $1 \mathrm{~kg}$ kita lakukan visit, skrg hanya via telpon, tanya berat badan, asi lancar, reflek bagaiamana, mereka merasa senang karena diperhatikan" Perawat 6

"Selama ini, sebelum 1 minggu kontrol ke RS dijelaskan keluarga kalau dijelaskan iya iya dirumah lupa lalu telpn RS, yang home visit saat kita telpon kita belum ada prosedurnya akhirnya seingatnya saja, menanyakan reflek hisap dilakukan atau tidak" Perawat 7

\section{PEMBAHASAN}

Masa nifas dianggap sebagai masa sensitif di mana ibu lebih rentan mengalami tekanan psikologis. Pada ibu dengan bayi berat lahir rendah, proses adaptasi psikologis ibu berpengaruh terhadap perawatan Bayi BBLR. (WHO, 2020) menyatakan bayi baru lahir yang kecil dan sakit mungkin memerlukan tindak lanjut tambahan untuk menilai pemulihan, pemberian makan, dan berat badan. menjaga suhu, menyusui dengan baik dan ibu percaya diri dalam merawat bayinya. Orang tua dan pengasuh harus diedukasi dan diajarkan untuk membangun kepercayaan diri mereka dalam merawat bayi mereka di rumah. Penelitian (Lee et al., 2019) menunjukkan ibu dengan bayi BBLR memiliki beberapa perubahan emosional dalam perawatan bayinya mulai dari awal perubahan metode pengasuhan, membentuk ikatan intim ibu-anak dan kekhawatiran dan harapan tentang perkembangan anak. Hal ini menunjukkan bahwa program tindak lanjut dengan intervensi dini diperlukan untuk meningkatkan kepercayaan diri ibu dalam keterampilan mengasuh anak dapat meningkatkan keterikatan ibu dan kualitas hidup keluarga dengan BBLR.

ASI adalah senyawa biologis yang memenuhi keseimbangan nutrisi bayi. bayi BBLR memerlukan penggunan ASI Ekslusif untuk memeuhi kebutuhan pertumbuhan dan perkembangan dirinya. Hasil penelitian (Ahmadi et al., 2016) menyatakan bayi BBLR lebih rentan terhadap penyakit, dan lebih rentan untuk disusui daripada bayi lainnya. Bayi yang memiliki reflek hisap yang buruk membutuhkan perhatian dan pengawasan dari ibu dan keluarga ketika merawat bayinya di rumah, termasuk penggunan OGT/NGT sebagai alat bantu bayi untuk makan keluarga dan ibu perlu diberikan edukasi bagaimana cara menggunakan dan membersihkan OGT/NGT agar bayi tidak mengalami resiko infeksi dalam penggunaannya.Hasil penelitian Beberapa Bayi BBLR merupakan Bayi prematur yang tidak dapat mengkoordinasikan mengisap atau memiliki reflek hisap yang buruk, menelan dan bernapas dan karenanya akan tergantung pada metode pemberian makan alternatif yaitu NGT/OGT, memberi makan cangkir, penggunaan botol dengan ASI perah.

Upaya yang dapat dilakukan untuk mencegah terjadinya hipotermi pada bayi salah satunya dengan menggunakan metode Kanggoro Mother Care (KMC). Metode perawatan bayi prematur dan bayi BBLR dimana bayi dijaga dalam kontak kulit ke kulit dengan ibu, Metode ini bertujuan untuk meningkatkan kelangsungan hidup bayi baru lahir. Efek fisiolofis dan perilaku yang menguntungkan dari KMC untuk bayi yaitu : termoregulasi yang lebih baik, peningkatan stabilitas kardiorespitasi, resiko infeksi yang lebih rendah dan pertumbuhan yang lebih cepat, siklus tidur yang lebih baik. Pada ibu yang menyusui dengan melakukan KMC terjadi peningkatan pemberian $\mathrm{ASI}$, mengurangi kecemasan ibu dan meningkatkan keterikatan ibu dan bayi (Rahman, 2017). Pelaksanaan KMC membutuhkan dukungan keluarga pada pelaksanaanya, KMC tidak hanya dilakukan pada ibu saja, tetapi dapat digantikan oleh keluarga bayi dalam kondisi baik yang tidak mengalami masalah kesehatan dan tidak merokok. penelitian (Ayele et al., 2021) menyatakan dukungan berasal dari dari suami, penyuluh kesehatan dan keluarga dan pemahaman ibu tentang pentingnya KMC menjadi faktor peningkatan signifikan menerapkan KMC di rumah. Bayi BBLR tidak direkomendasikan untuk mandi telalu lama. Mandi yang terlalu lama menyebabkan kehilangan energi, hipotermia dan meningkatkan risiko infeksi (Lunze \& Hamer, 2012). Edukasi kepada pengasuh untuk menunda mandi, kurangi frekuensi dan intensitasnya hingga stabil secara fisiologis dapat digunakan untuk mencegah terjadinya hipotermia pada BBLR pada bayi (Colwell, 2015).

Bayi berat lahir sangat rendah (BBLR) berisiko tinggi mengalami infeksi selama periode antenatal, prenatal, dan postnatal. Pencegahan, diagnosis yang tepat, dan pengobatan akan menurunkan angka morbiditas dan mortalitas yang tinggi terkait dengan sepsis pada bayi BBLR (Hilaire et al., 2021). Ada kebutuhan untuk meningkatkan pengetahuan tentang faktor risiko dan mengatasi penyimpangan dalam pengenalan dan perawatan Bayi BBLR. Konseling tentang perawatan neonatal yang direkomendasikan harus dimulai selama perawatan antenatal dan 
diulangi dalam jangka waktu yang lama hingga perawatan postpartum (Asmuji \& Indriyani, 2016). Hasil penelitian Asmuji (2020) menunjukkan bahwa terdapat pengaruh model pendidikan postnatal melalui pendekatan FCMC terhadap persepsi ibu postpartum dan keluarganya tentang perawatan diri selama masa nifas segera, perawatan bayi dan perawatan diri di usia dini. ada juga pengaruh upaya penyuluhan model pendidikan nifas melalui FCMC terhadap persepsi penyuluh kesehatan dengan nilai $p \quad 0,00$. Penelitian ini merekomendasikan agar model pendidikan postnatal FCMC sebagai optimalisasi kompetensi mothering diimplementasikan sebagai salah satu upaya dalam menurunkan Angka Kematian Ibu dan Bayi secara berturutturut

Kunjungan perawat ke rumah ibu dengan bayi BBLR berdampak positif untuk perkembangan bayi BBLR. Hasil penelitian (Prabhakaran \& Arulappan, 2021) menunjukkan efektivitas program pengajaran terstruktur yang dipimpin perawat (NLSTP) pada pengetahuan dan praktik ibu dari bayi BBLR efektif meningkatkan pengetahuan ibu dan keluarga merawat bayi BBLR.

\section{KESIMPULAN}

Bayi BBLR memerlukan perhatian dan perawatan tambahan selama di rawat dirumah untuk meminimalkan resiko kesehatan bayi. Peningkatan perhatian untuk menjaga bayi BBLR agar tetap hangat dalam bentuk FCMC berintergatsi pada ibu, keluarga serta perawat seperti KMC, bantuan untuk inisasi menyusui, seperti membantu ibu bagaimana cara memerah ASI, cara menggunakan NGT OG dan dukungan tambahan untuk menyusui dan memantau pertumbuhan perkembangan bayi dengan cara melalukan home visit oleh perawat dapat mengoptimalkan perawatan Bayi BBLR di rumah.

\section{REFERENS}

Ahishakiye, A., Abimana, M. C., Beck, K., Miller, A. C., Betancourt, T. S., Magge, H., Mutaganzwa, C., \& Kirk, C. M. (2019). Developmental outcomes of preterm and low birth weight toddlers and term peers in Rwanda. Annals of Global Health, 85(1), 111. https://doi.org/10.5334/aogh.2629

Ahmadi, S., Kazemi, F., Masoumi, S. Z., Parsa, P., \& Roshanaei, G. (2016). Intervention based on BASNEF model increases exclusive breastfeeding in preterm infants in Iran: A randomized controlled trial. International Breastfeeding Journal, 11(1), 110. https://doi.org/10.1186/s13006-016-0089-2

Asmuji, \& Indriyani, D. (2016). Model Family Centered Maternity Care sebagai strategi Optimalisasi Competent Mothering. Ners Airlangga, 11(1), 1728. https://ejournal.unair.ac.id/JNERS/article/view/1905/pdf_17
Ayele, M. W., Wubie, M. B., \& Ayele, S. A. (2021). Proportion of mothers practicing kangaroo mother care at home and factors influencing the practices following hospital discharge, South Wollo, Ethiopia. Journal of Neonatal Nursing, 27(2), 118-122. https://doi.org/10.1016/j.jnn.2020.05.006

Badan Pusat Statistik Jawa Tengah. (2019). Profil Kesehatan Provinsi Jawa Tengah. 2019. Semarang. Jawa Tengah.

Benson Atitwa, E. (2015). Socio-Economic Determinants of Low Birth Weight in Kenya: An Application of Logistic Regression Model. American Journal of Theoretical and Applied Statistics, 4(6), 438. https://doi.org/10.11648/j.ajtas.20150406.14

Colwell, A. (2015). To bathe or not to bathe: The neonatal question. Neonatal Network, 34 (4), 216-219. https://doi.org/10.1891/0730$\underline{0832.34 .4 .216}$

Dinas Kesehatan Kabupaten Tegal. (2018). Profil Kesehatan Kabupaten Tegal Tahun 2018. Diakses pada tanggal 26 Oktober 2020. http://data.tegalkab.go.id/en/dataset/profilkesehatan-kabupaten-tegal-tahun-2018

Deshpande Jayant D, Phalke D, Bangal V, Peeyuusha D.(2011). Maternal risk factors for low birth weight neonates: a hospital-based case-control study in rural areas of western maharashtra, India. Natl J Community Med. 2011;2(3):394398

Hilaire, M., Andrianou, X. D., Lenglet, A., Ariti, C., Charles, K., Buitenhuis, S., Van Brusselen, D., Roggeveen, H., Ledger, E., Denat, R. S., \& Bryson, L. (2021). Growth and neurodevelopment in low birth weight versus normal birth weight infants from birth to 24 months, born in an obstetric emergency hospital in Haiti, a prospective cohort study. BMC Pediatrics, 21(1), 1-16. https://doi.org/10.1186/s12887-02102605-3

Harshita Prabhakaran. (2020). Effectiveness of Nurse led structured teaching programme on knowledge and practice of postnatal mothers on low birth weight care. Journal of Neonatal Nursing $x x x(x x x x) x x x$.https ://doi.org/10.1016/j.jnn.2020.09.004

International Childbirth Education Association. (2018). Family Centered Maternity Care. Accessed on October 26, 2020. www.icea.org.

Janmejaya Samal . (2016). Assessing the Family Centered Maternity Care Practices of a Community Health Center in Chhattisgarh, India. Asian Journal of Pharmaceutics • Jul-Sep 2016 (Suppl) • 10 (3) | S308

Kementerian Kesehatan. (2019). Data dan Informasi profil Kesehatan Indonesia 2019. Jakarta : Kementerian Kesehatan.

Lee, J., Kang, J. C., \& Ji, E. S. (2019). Experiences of Mothers' Attachment in a Follow-Up Program Using Early Intervention for Low-Birth-Weight Infants. Asian Nursing Research, 13(3), 177-183. https://doi.org/10.1016/j.anr.2019.04.004

Lunze, K., \& Hamer, D. (2012). Thermal protection of the newborn in resource-limited environments. 
Journal of Perinatology, 32(5), 317. https://doi.org/10.1038/jp.2012.11

Martinson, M L. Choi K H. (2019). Low birth weight and childhood health: the role of maternal education Annals of Epidemiology $39 \quad(2019) \quad 39 \mathrm{e} 45$

https://doi.org/10.1016/i.annepidem.2019.09.006 Hamid, AYS \& Ibrahim K. 2017. Pakar Teori Keperawatan dan Karya Mereka. Singapore: Alligood MG : Elsevier.

Mathewson $\mathrm{KJ}$, Chow $\mathrm{CH}$, Dobson KG, Pope El, Schmidt LA, Van Lieshout RJ. (2017). Mental health of extremely low birth weight survivors: A systematic review and meta-analysis. Psychological bulletin. 2017; 143(4):347-83. https://doi.org/10.1037/bul0000091 PMID: 28191983.

Prabhakaran, H., \& Arulappan, J. (2021). Effectiveness of Nurse led structured teaching programme on knowledge and practice of postnatal mothers on low birth weight care. Journal of Neonatal Nursing, 27(3), 200-205. https://doi.org/10.1016/j.jnn.2020.09.004
Rahman, M. (2017). Kangaroo Mother Care for Low Birth Weight Babies: A Randomized Controlled Trial in a Tertiary Care Hospital of Bangladesh. Journal of Pediatrics \& Neonatal Care, 7(2). https://doi.org/10.15406/jpnc.2017.07.0028 5

Ruairi C.Robertson Amee R.Manges Brett Finlay, Andrew J. Prendergast. (2019). The Human Microbiome and Child Growth First 1000 Days and Beyond Trends in Microbiology, February 2019, Vol. 27, No.2

Sugiarti, Yeni Rustina, Defi efendi. (2020) Increasing the knowledge and cofidence of the mothers ini caring for low birth weight babies through education from the maternal and child health handbook. Junal Keperawatan Soedirman 15(2) 2020: $11-23$

WHO. (2020). Standards for improving the quality of care for small and sick newborns in health facilities. https://www.who.int/publications/i/item/9789 240010765 